\title{
An evaluation of a vocational training scheme for dental therapists (TVT)
}

\author{
A. D. Bullock, ${ }^{1}$ H. C. Falcon, ${ }^{2}$ S. Mehra ${ }^{3}$ and K. Stearns ${ }^{4}$
}

IN BRIEF

- Provides a description of the new vocational training scheme for dental therapists, an evaluation of strengths and identification of areas for development.

- The scheme clearly provides a supportive practice environment for the further development of dental therapy skills in treating different patient groups.

- The scheme increased the trainers' likelihood of employing a therapist.

Commissioned by NHS Education South Central (NESC) Postgraduate Dental Deanery, this work provided an external, independent formative evaluation of the Dental Therapists Vocational Training (TVT) scheme in its first year of operation. Undertaken between March-September 2009, the evaluation engaged with all those involved in the TVT scheme: the newly qualified dental therapists ( $n=9$; group discussion and questionnaire; portfolio extracts) and interviews with their trainers $(n=9)$, Associate Postgraduate Dental Dean and TVT Scheme Adviser. Most of those on the scheme did not feel well prepared for work at the point of initial qualification and benefitted from enhancement of confidence and skills. Although the number of treatments undertaken by each of the trainees varied considerably, there was commonality in terms of treatment types. Benefits for trainers included the opportunity to work with a dental therapist and develop a better understanding of their role. They praised the trainees' skills with nervous patients and children and their preventative work. A therapist on the team released the dentist for more complex treatments. Challenges related to the recruitment of trainees and trainers, the relative lack of knowledge about the work of dental therapists, concerns about maintaining the range of therapy skills and issues about UDA (unit of dental activity) distribution. There was widespread support for a mandatory TVT scheme. This scheme could be improved by providing further guidance on the amount and type of clinical experience required.

\section{INTRODUCTION}

\section{Context}

In dentistry only a small portion of dental treatment is complex and there is considerable scope to delegate routine treatments to dental therapists. ${ }^{1}$ In July 2002 the General Dental Council (GDC) allowed dental therapists to work in general dental practice and extended their duties. The skills and abilities of each dental registrant group have been set out by the GDC. ${ }^{2}$ Although there is the potential to delegate further (in New Zealand for example, therapists can diagnose and formulate their

\footnotetext{
1*Professor and Director of CUREMeDE, Cardiff Unit for Research and Evaluation in Medical and Dental Education, Cardiff University School of Social Sciences, Glamorgan Building, King Edward VII Avenue, Cardiff, CF10 3WT; ${ }^{2}$ Postgraduate Dental Dean, ${ }^{3}$ Associate Postgraduate Dental Dean, ${ }^{4}$ Dental Therapist Vocational Training Advisor, Oxford and Wessex Deaneries (NHS Education South Central), The Triangle, Roosevelt Drive, Headington, Oxford OX3 7XP

*Correspondence to: Professor Alison Bullock Email: bullockad@cardiff.ac.uk
}

\section{Refereed Pape}

Accepted 24 June 2010

DOI: $10.1038 /$ sj.bdj.2010.818

${ }^{\circledR}$ British Dental Journal 2010; 209: 295-300 own treatment plans), evidence suggests that in the UK the full extent of currently permitted duties is not widely used in practice. A significant concern expressed in the literature is that the therapy part of the hygienist-therapist work may be under utilised, confidence affected and the therapist de-skilled. ${ }^{3}$ One of the challenges therapists face is lack of knowledge about the extent of their duties among general dental practitioners (GDPs)., ${ }^{4,5}$ The GDPs themselves are concerned about the costeffectiveness of employing a therapist ${ }^{6,7}$ and report the availability of surgery space as another barrier. Some are also concerned about patient acceptability of treatment by a therapist. ${ }^{8}$

Despite these challenges, there is significant capacity to use therapists for much routine dentistry thus releasing the dentist for more complex treatments. ${ }^{1}$ Whether the less complex dental treatments are carried out by dentists or dental therapists is in part influenced by local commissioning. The UDA (unit of dental activity) is the contract currency in England and Wales and, 'Depending on the complexity of a course of routine treatment delivered, the dentist is awarded either one, three or 12 UDAs.9 Little information is available on the average number of UDAs earned by different parts of the service although a well referenced guide is that used for calculating net funding for vocational training (VT) where the Department of Health states: 'it is assumed that a whole-time equivalent trainee will complete 1,875 Units of Dental Activity (UDAs) over the course of a year. This is designed to reflect a reasonable level of activity for a trainee receiving a broad training experience over the 12 -month period. ${ }^{10}$

\section{The TVT scheme}

NHS Education South Central (NESC), which includes Oxford and Wessex Postgraduate Deaneries, was the first in England to run a vocational training scheme for dental therapists. Similar to vocational training (VT) for dentists, TVT aims to support the development of the clinical and personal skills of the newly qualified dental therapist. The scheme was introduced in response to anecdotal evidence which suggested that on qualification, many newly qualified dental therapists were practising 
solely as hygienists in the private sector. This was of concern to the Educational Commissioners in NHS Education South Central who fund pre-qualification therapist training programmes in Portsmouth and London. The TVT scheme was funded specifically to encourage newly qualified dental therapists to work in an NHS general dental practice setting in the 0xford and Wessex Deaneries.

The scheme runs for 12 months, beginning in September. Its first year of operation was 2008-09. Applications were invited from newly qualified therapists through national advertisement and open competition (satisfying equal opportunities requirements). Features of the scheme include training practices with an appointed trainer, a study day programme (one day a month), a learning portfolio, and workplace based assessments. As part of the programme, the trainees are required to undertake at least three (out of seven) Faculty of General Dental Practice (FGDP) key skills modules.

The model for TVT is part-time with trainees working as a therapist in an approved practice for three days a week. Typically they work as hygienists for the other days. Trainers are recruited by open competition from NHS dental practices within the NESC area. The scheme includes an initial programme for training the trainers. Trainers receive a small, practice reimbursement grant and the Deanery pays half the therapist's salary. Trainers pays the therapists in full each month.

\section{AIMS}

The purpose of the study was to evaluate the NESC new TVT scheme, identifying benefits and challenges as perceived by those involved (the trainees, the trainers in practice, the Scheme Adviser and the Associate Dean responsible for the programme) and as revealed in extracts from the trainees' portfolios. This study was primarily educational in focus and intended to report on the extent to which the scheme supported the development of the therapist.

\section{METHOD}

As an independent, external evaluation, the work was conducted by the first author in three main phases in the period March to September 2009. In the first preparatory phase key messages from the wider literature were distilled; an information sheet and consent form for the participants, and data collection instruments were drafted; research ethics forms completed; and faceto-face discussion held with the Associate Dean. Data gathering was the focus of the second phase and included telephone discussion with the TVT scheme Adviser; a short structured interview with the trainers $(n=9)$; group discussion followed by a questionnaire to all TVTs $(n=9)$ distributed face-to-face on a study day; and extracts from portfolios on treatments undertaken. Interviews with trainers typically lasted 20-30 minutes and were conducted either face-to-face (where notes were made at the time and filled out later) or over the telephone (which were recorded and summarised). Interviews and questionnaires explored views on perceived benefits of the programme along with challenges and areas for development. Responses to questions asked in the interviews and the open questions on the questionnaires were analysed for themes and summarised. Treatment information, extracted from the portfolios (with permission) included numbers of patients seen and treatments performed. In the final phase, analysis was completed and a report prepared.

Research ethics approval was obtained from Cardiff University, School of Social Sciences Research Ethics Committee (SREC/503).

\section{RESULTS}

\section{The trainers}

All trainers worked at multi-surgery practices, a number had been VT trainers recently and several had a vocational dental practitioner (VDP) as well as a therapist on the TVT scheme at the practice. One practice was a community dental service clinic with a therapist as trainer. One practice had two trainees (linked to different trainers).

Three main reasons for choosing to take part in the TVT scheme were identified by trainers. Five of them noted that they had taken on a training role before (four as VT trainers and one as a nurse trainer) and that training was seen as part of the ethos of the practice. For four this was their first experience as a trainer and most saw this as a possible step to becoming a Dental Foundation Trainer (DFT) in the future: TVT training was seen to be less of a commitment than DF training. Another common reason, mentioned by four trainers, was that the scheme provided them with the opportunity to find out more about working with a therapist. Another spoke of her general commitment to the concept of the scheme.

Trainers were asked to describe the nature of the support they provided the therapist in the practice. Most commonly mentioned strategies included 'an open door policy' and the use of the tutorials (each mentioned by five trainers). Three referred to being 'in and out' of the trainee's surgery frequently in the first month in particular. Two talked of the observations related to the assessments and one reported that s/ he nursed for the therapist on occasions. Another made a video recording which was played back and discussed in a tutorial.

\section{Overview of the therapists' activity}

The practice activity log was extracted from the portfolios for months 9 and 10 . The average number of UDAs completed for month 9 was 120 although the range was very large, from 32 to 186 . For month 10 the average was 138 UDAs but again the range was sizeable, from 64 to 262 . These periods did contain some absence from practice.

The number of adult and child patients seen by the different therapists in months 9 and 10 varied hugely. The range for adult patients was 10-109 appointments in month 9 and 20 to 93 in month 10 . The means were fairly stable at 56 and 60 appointments for months 9 and 10 respectively. The range of child appointments for month 9 was 3 to 43 and for month 10, 10 to 59. Generally, fewer child than adult patients were seen with the mean number of child appointments being 24 for month 9 and 28 for month 10.

Extracts from the portfolios for months 9 and 10 were also taken to report clinical activity. These showed huge variation in numbers of activities undertaken by different trainees although there was also commonality in terms of most frequent types of activity, namely scaling and restorations. For five of the trainees, restorations were more commonly performed on adult patients in months 9 and 10, most commonly amalgam class II. The others carried out more restorations in this period on child patients. 
The use of fissure sealants varied across the group as a whole and for individuals by month; for example, one TVT completed 16 fissure sealants in month 9 and 46 in month 10 (these numbers were unusually high). Similar variation was shown for radiographs. For example, another TVT completed 19 radiographs in month 9 and 1 in month 10.

\section{Skills development}

Six of the nine trainers interviewed thought that their trainee's initial clinical skills met or exceeded their expectations. However, three were 'shocked' at the therapist's lack of experience of clinical procedures but clearly blamed the prior training, not the individual.

In an attempt to assess change in level of confidence, from the point of qualification to the end of TVT, for general aspects of their work, the therapists were asked to rate their level of confidence (on a 6-point scale) at these two points in time. Specifically, in the questionnaire they were presented with a list and asked: 'For each of these aspects of therapy work, please first think back to how you felt at the end of your basic dental qualification and indicate your level of confidence (a) at graduation and then now, (b) at the end of TVT'. Table 1 lists the aspects of work and gives the change in rating for each respondent (ranging from -1 to 4 ) and an aggregate of the changed ratings (total) across the group as a whole. Clinical judgement showed the greatest change in rating. Restorative dentistry also showed sizeable changes in conf1dence. The experience clearly also developed confidence in communication skills and paediatric dentistry for most of the therapists. Similarly, confidence levels in investigation and referral and preventative dentistry increased and all rated increased confidence in professionalism. Looking at the bottom of the table, little change in confidence was shown for treating patients under conscious sedation (few had experience of this) and changes in confidence levels in pharmacology were also low.

For a separate list of specific clinical activities, therapists were asked to rate their level of confidence at the end of TVT. These responses were compared to their self ratings, extracted from their portfolios which were given at the start of TVT (ie at graduation). Principal findings
Table 1 Changes in confidence from graduation(basic dental therapy qualification) to end of TVT for 16 aspects of work

\begin{tabular}{|c|c|c|c|c|c|c|c|}
\hline \multirow[b]{2}{*}{ Aspects of work } & \multicolumn{7}{|c|}{ Change in rating } \\
\hline & -1 & 0 & 1 & 2 & 3 & 4 & Total \\
\hline Clinical judgement & 0 & 0 & 2 & 6 & 1 & 0 & 17 \\
\hline Restorative dentistry & 0 & 0 & 3 & 5 & 1 & 0 & 16 \\
\hline Communication skills & 0 & 1 & 2 & 4 & 2 & 0 & 16 \\
\hline Paediatric dentistry & 0 & 2 & 1 & 4 & 1 & 1 & 16 \\
\hline Investigation and referral & 0 & 1 & 2 & 5 & 1 & 0 & 15 \\
\hline Preventative dentistry & 0 & 1 & 3 & 3 & 2 & 0 & 15 \\
\hline Professionalism & 0 & 0 & 5 & 3 & 1 & 0 & 14 \\
\hline Legislation & 0 & 2 & 3 & 2 & 2 & 0 & 13 \\
\hline Clinical assessment and examination skills & 0 & 1 & 4 & 4 & 0 & 0 & 12 \\
\hline Cross infection control & 0 & 2 & 2 & 5 & 0 & 0 & 12 \\
\hline Medical record keeping & 0 & 1 & 5 & 3 & 0 & 0 & 11 \\
\hline History taking & 0 & 1 & 5 & 3 & 0 & 0 & 11 \\
\hline Medical emergencies & 0 & 2 & 5 & 1 & 1 & 0 & 10 \\
\hline Dental pathology & 0 & 1 & 6 & 2 & 0 & 0 & 10 \\
\hline Pharmacology & 1 & 1 & 6 & 1 & 0 & 0 & 7 \\
\hline Treating patients under conscious sedation & 0 & 5 & 4 & 0 & 0 & 0 & 4 \\
\hline
\end{tabular}

Table 2 Therapists' views on the TVT scheme

\begin{tabular}{|c|c|c|c|c|c|c|}
\hline \multirow[t]{2}{*}{ Statement } & \multicolumn{3}{|c|}{$\begin{array}{l}\text { Strongly } \\
\text { disagree }\end{array}$} & \multicolumn{3}{|c|}{$\begin{array}{r}\text { Strongly } \\
\text { agree }\end{array}$} \\
\hline & 1 & 2 & 3 & 4 & 5 & 6 \\
\hline $\begin{array}{l}\text { [1] A TVT scheme should be mandatory for } \\
\text { all newly graduated therapists }\end{array}$ & 0 & 0 & 0 & 1 & 3 & 5 \\
\hline [2] I would recommend this TVT programme to others & 0 & 1 & 0 & 1 & 1 & 6 \\
\hline $\begin{array}{l}\text { [3] I am concerned that I won't be able to maintain } \\
\text { the full range of my therapy skills }\end{array}$ & 0 & 1 & 0 & 1 & 2 & 5 \\
\hline $\begin{array}{l}\text { [4] I am keen to use the full range of my therapy } \\
\text { skills in my next job }\end{array}$ & 0 & 0 & 0 & 2 & 3 & 4 \\
\hline [5] I feel well integrated into the practice & 0 & 0 & 0 & 2 & 3 & 4 \\
\hline $\begin{array}{l}\text { [6] The workplace based assessments provided } \\
\text { good feedback on my performance }\end{array}$ & 0 & 0 & 0 & 2 & 4 & 3 \\
\hline $\begin{array}{l}\text { [7] The way therapists were matched to training } \\
\text { practices worked well }\end{array}$ & 0 & 0 & 0 & 3 & 3 & 3 \\
\hline [8] My trainer provided good support in the practice & 1 & 0 & 0 & 1 & 4 & 3 \\
\hline $\begin{array}{l}\text { [9] The learning portfolios helped me reflect on } \\
\text { my progress }\end{array}$ & 0 & 0 & 0 & 4 & 3 & 2 \\
\hline $\begin{array}{l}\text { [10] The application process for the TVT scheme was } \\
\text { straight forward }\end{array}$ & 0 & 0 & 1 & 3 & 3 & 2 \\
\hline $\begin{array}{l}\text { [11] The study day programme was well matched to } \\
\text { my learning needs }\end{array}$ & 0 & 0 & 0 & 5 & 3 & 1 \\
\hline [12] It was worthwhile doing the FGDP Key Skills modules & 0 & 1 & 1 & 3 & 2 & 2 \\
\hline $\begin{array}{l}\text { [13] I feel the undergraduate course prepared me well } \\
\text { for starting work as a therapist }\end{array}$ & 0 & 2 & 4 & 1 & 1 & 1 \\
\hline $\begin{array}{l}\text { [14] I have a clear plan for my continuing professional } \\
\text { development (CPD) }\end{array}$ & 0 & 1 & 3 & 4 & 1 & 0 \\
\hline [15] I enjoyed the FGDP Key Skills modules & 2 & 0 & 4 & 2 & 1 & 0 \\
\hline
\end{tabular}


are summarised here but not reported in detail. The greatest self-rated improvement in confidence was shown for extractions. Change in confidence was high for most types of restorations as well as inferior dental block anaesthesia, radiographs, pulpotomy and temporary dressings. Little change was shown for debridement, recording indices and monitoring, and oral assessment.

\section{Therapists' views}

The therapists' views on the TVT scheme were sought by asking them to respond to a number of statements, rating their level of agreement on a 6-point scale (where 1 = strongly disagree and $6=$ strongly agree). The results are given in Table 2 where statements are arranged by level of agreement (rated 5 or 6). Most of those on the scheme did not feel well prepared for starting work at the point of qualification (6 disagreed with statement 13, giving a rating of 2 or 3) and there was widespread support for some kind of mandatory TVT scheme (all gave a rating of 4 or more for statement 1).

All trainees thought that the workplace based assessments provided good feedback on their performance and that the trainer gave good support (indicated by ratings of 4 or more for statements 6 and 8). All agreed that the learning portfolios helped aid reflection on progress and that the study day programme was well matched to learning needs (indicated by ratings of 4 or more for statements 9 and 11). Most (7) agreed that it was worthwhile doing the FGDP Key Skills modules (statement 12) despite only 3 enjoying it (as indicated by ratings of 4 or 5 for statement 15).

All therapists felt well integrated into their training practices (statement 5) and all bar one would recommend the TVT programme to others (indeed 6 indicated strongest agreement by giving a rating of 6 for statement 2). Eight of the nine therapists agreed that the way they were matched to training practices worked well (statement 7) and the application process was straightforward (statement 10).

All gave a rating of at least 4 for statement 4 indicating that they were keen to make use of the full range of their therapy skills in their next job. However, strong agreement was also given to statement 3 which expressed concern about being able to maintain the full range of therapy skills. Responses to statement 14 ('I have a clear plan for my CPD') were very mixed.

\section{Trainers' views}

Some of these views were echoed in the interviews with the trainers. They also were in support of some kind of mandatory TVT scheme. The Associate Dean argued the need for a training scheme for therapists akin to VT for dentists (typically DF year 1) on the grounds that, to maintain skills, newly qualified therapists needed to practise, develop and embed them into their workplace activities.

Benefits of having a therapist on the team, as identified by trainers, included the skills and time they have for nervous patients and children and the preventative work they do. Illustrative comments from trainers include:

'She's managed to do treatments on children that we wouldn't have managed. It's been good having someone to spend that bit of time with cases.'

'A lot of patients have come back six months later with fantastically improved oral hygiene which we always struggle to achieve so I think from that point of view we've had a good result from a lot of patients which is of benefit to the practice.'

Therapists were seen as being able to free up the dentist's time for more complex (and interesting) treatments. One commented: 'for six months I barely did a filling and I liked that'. Other trainers observed:

'It eases the workload of the dentist. It reduces waiting times for patients; whereas before they might have waited 8-10 weeks to see me for a filling, now it can be done in a week which is obviously an advantage for the patient.'

'If on the NHS treatment plan you've got a patient with a lot of simple restorations it takes up a lot of time and the therapist can be doing that, freeing your time up to do other treatment and maybe other more complicated treatments - crowns, dentures and things like that. In a busy practice it can help with your time.'

Views on the workplace based assessments and the portfolios were generally positive with the assessments providing useful feedback on progress. However, a few trainers thought the amount of paperwork unnecessary.

All the trainers would recommend taking part in the scheme to other dentists and the experience had tended to increase their likelihood of employing a therapist: the scheme provided opportunity for dentists to try out working with a therapist and five of the trainers had offered their TVT trainee work in the practice.

\section{Challenges}

Some of the challenges identified by the participants have been highlighted in the wider literature and relate more broadly to the employment of dental therapists in the dental team and not specifically to the TVT scheme itself.

As was shown in Table 2, the therapists on the scheme were keen to continue to use their dental therapy skills but were concerned that they might not be able to maintain their skills in the future. GDPs' relative lack of knowledge about the work of dental therapists was raised as an issue by those on the scheme. The main challenges to working as a dental therapist were identified as: educating dentists about what therapists can do (indicated by seven trainees) or showing dentists the importance of the role (one trainee). In the words of trainees, these challenges where described as:

'Proving that I am competent and able to show the dentists that my role is very important in the dental team.'

'Dentist attitudes to what we do - not knowing what we can do and how it can work in practice.'

One trainer admitted: 'If I'd not been part of this scheme, I wouldn't have known their remit'.

Other challenges identified by the therapists included: difficult patients (attitudes) (4); finding a job (3); working without support (1); poor money (1); poor equipment/ resources (1); educating patients about the therapist's role (1).

A concern voiced by the trainers related to the costs of employing a therapist. Different models of UDA distribution were described. One trainer outlined and commented on three models: 
1. The UDAs are split between the dentist (associate) and the therapist. The concern here was that the dentist (associate) feels they are 'giving away' UDAs

2. The therapist's salary is divided by the number of dentists and the UDAs shared

3. The dentist (associate) keeps all the UDAs. The practice then hits higher targets which was described as 'benefitting everyone if you have higher targets. It can be invaluable for lots of NHS practices. Invaluable.'

The trainers used different models of UDA distribution and would like input on possible methods to be included in their trainer preparation programme. All the trainers would recommend employing a therapist to other dentists, although for some the recommendation was conditional on the practice having a large enough NHS contract and sufficient surgery space.

The TVT scheme faced the dual challenge of recruiting both trainee therapists and trainer dentists in sufficient numbers. Possible explanations as to why fewer than anticipated newly qualified therapists applied to the scheme related to location and the attraction of earning more as a hygienist. Barriers to becoming a trainer were seen as relating to competing opportunities to become a DF/VT trainer and funding issues.

\section{DISCUSSION}

That the trainees on this scheme did not feel well prepared for starting work at the point of qualification as a dental therapist demonstrates that the opportunity to develop confidence and skills should be seen as a key benefit of the programme. Starting work without the chance to embed these new skills could result in them not being used and the therapist becoming deskilled over time. The on-going challenge recognised by the trainees was the need to continue to use and maintain the full range of duties.

Given the centrality of skills development, the extent of variation in terms of numbers of treatments undertaken by the therapists in the different practices needs review. It may be appropriate to require the completion of either minimum numbers of different treatments or, because there were common patterns to treatment types, the establishment of a minimum number of appointments or UDAs over the year. However, it would be essential to be sensitive to the circumstances of the practice: how achievable a set number of UDAs is in part determined by the mix and treatment needs of patients, reflecting the demographics of the area. Further, treatment times need to be longer for the more challenging and medically compromised patients more commonly seen by dental therapists working in the community dental service.

Comparison with the 1,875 UDAs suggested for vocational dental practitioners indicates that perhaps some of the dental therapists on the TVT scheme were undertaking an equivalent pro rata amount. This scheme was based on three days a week which would suggest 1,125 UDAs for the year, pro rata. Assuming that the number of UDAs undertaken is likely to increase over the course of the scheme, one guide might be that the trainees should be looking to undertake an average of 60 UDAs per month in the first four months, perhaps increasing this to an average of 90 for months 5-8 and further, to 130 for the final four month period (months 9-12). The reported average activity, across the group, of 120 UDAs for month 9 and 138 for month 10 would be approximately in line with these suggestions. However, it should be highlighted that the averages reported by these therapists mask wide variation between trainees. There are a number of possible explanations for this variation including periods of leave as well as variation resulting from increases in certain child treatments during school holidays or reflecting a response to gaps in experience that the trainer has sought to address by relevant referrals.

In any discussion of UDAs, it is pertinent to note that it is likely that they will not be the sole currency in the future ${ }^{11}$ and that a broader range of measures will be introduced including those related to waiting times, emergency treatment, patient satisfaction and prevention, for which the dual qualified dental hygienist-therapist is well placed to deliver. ${ }^{12,13}$ Broadening the skill-mix of the dental team is predicted as a key future development of the workforce in dentistry. ${ }^{14}$ From first hand experience of working with a dental therapist, these trainers were able to recognise their contribution, particularly in relation to work with more challenging patients (children and anxious adults) and their preventative work.

Education can influence the acceptance of a broader skill-mix. Recent initiatives include joint activities for dental and hygiene-therapy students. ${ }^{15,16}$ Further study will be needed to explore whether initiatives which bring dentists and therapists together in practice allay the anxieties expressed by some GDPs. ${ }^{5}$ The views of trainers involved in this scheme demonstrated that it was an education for some of them in terms of developing a better understanding of the role of the therapist in the dental team. Shared learning, with dental foundation trainees and therapists within vocational training schemes, in paediatric dentistry for example, might serve to develop in the next generation of dentists, a deeper appreciate of the extent of a dental therapist's duties.

\section{CONCLUSION}

The many benefits alongside the challenges - related to the TVT scheme itself and more broadly to the employment of therapists within the dental team - have been summarised in this paper. By way of conclusion to this formative evaluation, it can be said without doubt that the individual newly qualified therapists who took part in the scheme benefited enormously: the TVT scheme enabled them to develop their skills and confidence. In their support for some kind of mandatory scheme, post initial qualification, these therapists were well aware that the dental therapy skills need to be practised soon after qualification. The TVT scheme provided a supportive practice environment for the further development of skills and all on the programme were ensured of varied clinical experience. The scheme also served to enhance dentists' knowledge of the skills of a dental therapist and improve opportunities for work.

The Associate Dean was cognisant of the challenge of recruiting sufficient numbers of both trainers and trainees. Advice on the distribution of UDAs might assist trainer uptake and the experience seems not to have deterred these trainers from considering the role again in the future. Attracting trainees 
may be a short term issue as this kind of programme, post initial qualification, becomes more commonplace. In a future which is likely to see the introduction of key performance indicators for preventative services (including diet and hygiene advice) ${ }^{9}$ for which the dual qualified dental hygienetherapist is well placed to deliver, there is reason to be optimistic about the role of therapists in general dental practice.

This work was supported by a grant from the NESC (Oxford and Wessex) Postgraduate Dental Deanery. We wish to acknowledge the contribution made by all the individuals who gave their time to this study. More broadly, this work was informed by studies undertaken at The University of Birmingham and the influence of Dr Vickie Firmstone in the approach to data gathering and instrument design is acknowledged.

1. Evans C, Chestnutt I G, Chadwick B L. The potential for delegation of clinical care in general dental practice. Br Dent J 2007; 203: 695-699.
2. General Dental Council. Scope of practice. London: GDC, 2009.

3. Jones $G$, Evans $C$, Hunter L. A survey of the workload of dental therapists/hygienist-therapists employed in primary care settings. Br Dent J 2007; 204: E5.

4. Gallagher J L, Wright D A. General dental practitioners' knowledge of and attitudes towards the employment of dental therapists in general practice Br Dent J 2003: 194: 37-41.

5. Ross M K, Ibbetson R J, Turner S. The acceptability of dually-qualified dental hygienist-therapists to general dental practitioners in South-East Scotland. Br Dent J 2007: 202: E8.

6. Harris R, Burnside G. The role of dental therapists working in four personal dental service pilots: type of patients seen, work undertaken and cost-effectiveness within the context of the dental practice. Br Dent J 2004; 197: 491-496.

7. Ward P. The changing skill mix - experiences on the introduction of the dental therapist into general dental practice. Br Dent J 2006; 200: 193-197.

8. Jones $G$, Devalia R, Hunter L. Attitudes of general dental practitioners in Wales towards employing dental therapists/hygienist-therapists. Br Dent $J$ 2007; 203: E19.

9. The Steele Review. NHS Denta/ Services in England: an independent review led by Professor Jimmy
Steele. London: Department of Health, 2009.

10. Department of Health. Implementing Local Commissioning for Primary Care Dentistry. Factsheet 6A Dental Vocational Training. Gateway Reference 7620. 2006.

11. Williams S A, Bradley S, Godson J H, Csikar J I, Rowbotham J S. Dental therapy in the United Kingdom: part 3. Financial aspects of current working practices. Br Dent J 2009; 207: 477-483.

12. Nilchian F, Rodd H D, Robinson P G. Influences on dentists' decisions to refer paediatric patients to dental hygienists and therapists for fissure sealants: a qualitative approach. Br Dent J 2009; 207: E13.

13. Dyer T A, Robinson P G. General health promotion in general dental practice - the involvement of the dental team. Part 2: A qualitative and quantitative investigation of the views of practice principals in South Yorkshire. Br Dent J 2006; 201: 45-51.

14. Gallagher J E, Wilson N H F. The future dental workforce? Br Dent J 2009; 206: 195-199.

15. Cotton C, Roberts A, Mackie I. Undergraduate perceptions of dental team working. ADEE Programme and Abstract Book 2009; F39.

16. Stewart F, Drummond J, Clarkson J, Young L. An investigation of job satisfaction of dental hygienist therapist tutors. ADEE Programme and Abstract Book 2009; F48. 